\title{
Optimization and Validation of HPLC Method for Simultaneous Determination of Vildagliptin, Pioglitazone Hydrochloride and Glimepiride in Bulk and Tablets
}

\author{
Mohammed M. Amin*1 ${ }^{1}$, Salah A. Abdel-Aziz ${ }^{1}$, Samia M. Mostafa ${ }^{2}$ and \\ Sobhy M. El-Adl ${ }^{3}$ \\ ${ }^{I}$ (Department of Pharmaceutical Chemistry, Faculty of Pharmacy/Al-Azhar University, Assuit, Egypt) \\ ${ }_{2}^{2}$ (Department of Medicinal Chemistry, Faculty of Pharmacy/Suez Canal University, Egypt) \\ ${ }_{3}^{3}$ (Department of Medicinal Chemistry, Faculty of Pharmacy/Zagazige University, Egypt)
}

\begin{abstract}
A new isocratic HPLC method is optimized and validated for simultaneous determination of Vildagliptin (VLD), Pioglitazone Hydrochloride (PIO) and Glimepiride (GLIM) in Bulk and tablets (Gliptus ${ }^{\circledR}$ and Amaglust ${ }^{\circledR}$ tablets). The chromatographic separation was achieved on a reversed-phase analytical column [Hypersilgold ${ }^{\circledR}$ C18 $(10 \mu \mathrm{m}, 150 \times 4.6 \mathrm{~mm})$ column] at ambient temperature. The separation was achieved by applying an isocratic elution system using acetonitrile and 0.05M potassium dihydrogen phosphate buffer, adjusted by orthophosphoric acid to a $\mathrm{pH}$ of 3.5 with a ratio of $(45: 55 \mathrm{v} / \mathrm{v})$ respectively, at a flow rate of 1.5 $\mathrm{ml} / \mathrm{min}$. The UV detection was performed at $200 \mathrm{~nm}$, the drugs calibration curves exhibited linear concentration ranges of 5-75, 3-45 and 1-8 $\mu \mathrm{g} / \mathrm{ml}$ for Vildagliptin, Pioglitazone and Glimepiride respectively with correlation coefficients not less than 0.9996.
\end{abstract}

Keywords: Glimepiride, HPLC, Pioglitazone Hydrochloride, Validation, Vildagliptin.

\section{Introduction}

Vildagliptin is (S)-1-[N-(3-hydroxy-1-adamantyl)glycyl] pyrrolidine-2- carbonitrile (Fig.1). Vildagliptinis a relatively new anti-diabetic drug used for controlling patient with type 2 diabetes mellitus. It is related to dipeptidyl peptidase-4 inhibitor drugs. Vildagliptinis are used either alone or in combination with other drugs such as metformin (MET), sulfonylurea or thiazolidinedione for better controlling of resistant patients. Combination of Vildagliptin and MET provides a superior HbA1c-lowering effect with a comparable overall tolerability profile and low risk of hypoglycemia [1] and [2]. Several methods have been reported for determination of Vildagliptin either alone or in combination with other drugs .The methods include spectrophotometric and spectrofluorometric methods [3-6], HPLC methods [7-12],UPLC method [13] and HPTLC method [14].

Pioglitazone hydrochloride is ( \pm )-5-(p-[2-(5-Ethyl-2-pyridyl)ethoxy]benzyl)-2,4-thiazolidinedione hydrochloride (Fig.2). Pioglitazone is one of thiazolidinediones group which is a class of oral anti-diabetic drugs that enhance target tissue insulin sensitivity. Pioglitazone has been shown to affect abnormal glucose and lipid metabolism associated with insulin resistance by enhancing insulin action on peripheral tissues [15].The literature review showed many methods for estimation of Pioglitazone hydrochloride which include the official method according to USP 36 [16] and reported methods such as spectrophotometric methods [17-21], HPLC methods [22-24] and HPTLC methods [25 and 26].

Glimepirideis1-((p-[2-(3-Ethyl-4-methyl-2-oxo-3-pyrroline-1-carboxamido)ethyl]phenyl)sulfonyl)-3(trans-4-methylcyclohexyl)urea (Fig.3). Glimepiride is a sulfonylurea anti-diabetic drug with prolonged effect and moreover, it maintains a more physiological regulation of insulin secretion than Glibenclamide during physical exercise, suggesting that there may be less risk of hypoglycemia with Glimepiride. It acts by increasing the secretion of insulin by $\beta$-cells of the pancreas[15].Glimepiride is officially reported in USP 36 [16], and BP 2013 [27]. Several methods have been reported for determination of Glimepiride either alone or in combined dosage forms. The methods include spectrophotometric [28-35], HPLC [22-24] and [36- 37] and HPTLC $[38,39]$. 


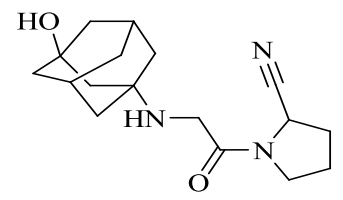

Fig.(1): Vildagliptin<smiles>CCc1ccc(CCOc2ccc(CC3SC(=O)NC3=O)cc2)nc1</smiles>

Fig.(2): Pioglitazone hydrochloride<smiles>CCC1=C(C)CN(C(=O)NCCc2ccc(S(=O)(=O)NC(=O)NC3CCC(C)CC3)cc2)C1=O</smiles>

\section{Experimental}

\subsection{Materials and reagents}

All experiments were performed using pharmaceutical grade authentic reference standards. Standard of Vildagliptin was kindly supplied as a gift samples by Inspire pharmaceutical company (Obour City, Egypt) while as, Pioglitazone hydrochloride and Glimepiride were generously gifted by Medical union pharmaceutical company (MUP), (Abo-sultan, Egypt). These reference standards were certified to contain 99.9, 100.55 and $99.82 \%$ (w/w), of Vildagliptin, Pioglitazone, and Glimepiride respectively.

Acetonitrile (ACN) and methanol (SDS, France) were of HPLC-grade, monobasic potassium dihydrogen phosphate (Winlab, UK); and orthophosphoric acid ( $\geq 85 \%$ ) purity (Riedel-de Haen, Germany) were all of analytical reagent grade. The water for HPLC was prepared in-house by double distillation then filtration through $0.45 \mu \mathrm{m}$ cellulose nitrate membrane filters (Chem Lab, Spain). All chemicals were used as received without further modification or purification.

The studied pharmaceutical preparations are Gliptus ${ }^{\circledR}$ (batch no. 507551) manufactured by EVA Pharma (Cairo, Egypt). It is Claimed to contain $50 \mathrm{mg}$ of Vildagliptin per tablet and Amaglust ${ }^{\circledR}$ (batch no. 610717) manufactured by Next Pharma(Cairo, Egypt), the pack declaring that a tablet contains 30 and $4 \mathrm{mg}$ of Pioglitazone and Glimepiride respectively were purchased from local drugstores.

\subsection{Instrumental and chromatographic conditions}

HPLC apparatus is equipped with a Surveyor ${ }^{\circledR}$ quaternary pump with Intel vacuum degasser (Thermo Scientific Co., USA), Surveyor ${ }^{\circledR}$ auto-sampler plus (Thermo Scientific Co., USA), Surveyor ${ }^{\circledR}$ photodiode array detector (PAD) (Thermo Scientific Co., USA). Computer with a software chromo quest 5 (Thermo Scientific Co., USA) for data collection and analysis auto-sampler vials $1.8 \mathrm{ml}$ screw cap (Thermo Scientific Co., USA).The separation and quantitation were made on Hypersil gold ${ }^{\circledR}$ C18 (10um, 150x4.6mm) column (Thermo Scientific Co., USA).

An isocratic mobile phase consisted of acetonitrile and $0.05 \mathrm{M}$ potassium dihydrogen phosphate buffer, adjusted by orthophosphoric acid to a $\mathrm{pH}$ of 3.5 with a ratio of $(45: 55 \mathrm{v} / \mathrm{v})$ respectively, at a flow rate of 1.5 $\mathrm{ml} / \mathrm{min}$.

Consort $\mathrm{P} 400^{\mathrm{TM}}$ is a digital $\mathrm{pH}$-meter used for the mobile phase $\mathrm{pH}$ adjustment. The mobile phase filtered using the vacuum filtration system equipped with $0.45 \mu \mathrm{m}$ nylon membrane filter and finally degassed for $30 \mathrm{~min}$ via an ultrasonic bath and allowed to run for 10 min prior each analysis. The detection wavelength was set at 200 $\mathrm{nm}$. All determinations were performed at ambient temperature $\left(25{ }^{\circ} \mathrm{C} \pm 1\right)$. Twenty $\mu 1$ were automatically injected.

\subsection{Standard solutions and calibration graphs}

Stock standard solutions were prepared separately to give a final concentration of $500 \mu \mathrm{g} / \mathrm{ml}$ for Vildagliptin, Pioglitazone and Glimepiride through dissolving an accurately weighed amount (50 $\mathrm{mg}$ ) in a total of $100 \mathrm{ml} \mathrm{ACN}$ for Vildagliptin. Pioglitazone and Glimepiride were dissolved separately in $100 \mathrm{ml}$ methanol. Working solutions for the standard calibration graphs were prepared immediately before usage by further dilutions of the stock solutions with the mobile phase to cover the concentration ranges of 5-75, 3-45, and 1-8 $\mu \mathrm{g} / \mathrm{ml}$ for Vildagliptin, Pioglitazone, and Glimepiride respectively. Three replicate each of twenty $\mu \mathrm{l}$ injections for each drug concentration level (simultaneously prepared) were made and directly chromatographed under the specified chromatographic conditions.

\subsection{Pharmaceutical formulations preparations}

The content of 20 tablets of Gliptus ${ }^{\circledR}$ and Amaglust ${ }^{\circledR}$ was weighed and separately grounded to get homogenous powder. A portion of each finely powdered drug equal to one tablet (according to the label claimed), equivalent to $50 \mathrm{mg}$ Vildagliptin, $30 \mathrm{mg}$ Pioglitazone and $4 \mathrm{mg}$ Glimepiride was accurately weighed and transferred to a $100 \mathrm{ml}$ capacity volumetric flask. Thirty milliliters methanol and thirty milliliters of ACN were added to the mixture; the mixture was dissolved via ultra-sonication for $30 \mathrm{~min}$ at ambient temperature and 
then diluted to the mark with the mobile phase. The solutions were filtered through $0.45 \mu \mathrm{m}$ nylon membrane filter discs [Millipore ${ }^{\mathrm{TM}}$, Milford, MA] before use. Further dilution was carried out using the mobile phase to suit the concentration domain covered by the calibration graphs. The solutions were chromatographed using the HPLC conditions described above and the concentrations of Vildagliptin, Pioglitazone and Glimepiride were calculated.

\subsection{HPLC method development and optimization}

\section{Results And Discussion}

A new reliable, sensitive and accurate RP-HPLC method is developed for simultaneous determination of Vildagliptin, Pioglitazone and Glimepiride in bulk and the method is applied successfully to the pharmaceutical preparations containing these compounds. This is the first time to separate these three drugs.

The chromatographic parameters such as detection wavelength, mobile phase composition, $\mathrm{pH}$ value and the flow rate were studied and optimized in order to provide an excellent assessment performance.

The UV absorption spectra of Vildagliptin, Pioglitazone, and Glimepiride prepared in the mobile phase were found to be in a region of $200-300 \mathrm{~nm}$ as represented in (Fig.4). It is obvious that each drug does strongly contribute to the overall absorption spectrum of the mixture, resulting in an extensive overlapping between the drugs absorption spectra. Thus, introducing an HPLC technique for the simultaneous analysis of Vildagliptin, Pioglitazone and Glimepiride in ternary mixtures will be more favored than applying any conventional (direct) first derivative or derivative ratio spectrophotometric methods.

\subsubsection{The effect of $\mathrm{pH}$ value of the buffer and percentage of organic modifier}

One of our crucial interests during the method development was the choice of suitable mobile phase components with suitable $\mathrm{pH}$ value for better separation of the investigated drugs without affecting their chemical entity. It was noticed that acidic $\mathrm{pH}$ values are preferred with Pioglitazone and Glimepiride during their own analyses. However, an analysis at $\mathrm{pH}$ value above 7 was to be avoided because it could damage the reversed silica-based analytical columns $\mathrm{C} 18$, when they are used frequently. By using $\mathrm{pH}$ value of $3.5 \mathrm{a}$ good baseline separation was achieved during the experimental study for Vildagliptin, Pioglitazone, and Glimepiride After several preliminary investigatory chromatographic runs, it was concluded that phosphate buffers gave better peak symmetry than their acetate and citrate counterparts. It was also noticed that peak shapes were improved with increasing the buffer ionic strength with a non-significant change beyond $0.05 \mathrm{M}$. In order to avoid salt precipitation that can affect the lifespan of the used analytical column. A $0.05 \mathrm{M}$ phosphate buffer was chosen for method validation. An initial mixture of methanol and phosphate buffer was tried in the ratio of $(40: 60, v / v)$. Unfortunately, Vildagliptin peak was observed to be forked and showed tailing this together with a delayed elution for Pioglitazone and Glimepiride that reached $a\left(t_{\mathrm{R}}\right)>8 \mathrm{~min}$ and $>20 \mathrm{~min}$, respectively. When methanol was replaced with acetonitrile at the same ratio a better separation was obtained but with relative tailing and forking for Vildagliptin peak. Increasing the acetonitrile concentration to more than $40 \%$ provided a more symmetrical Vildagliptin peak. Therefore, methanol was excluded again in the dilution process to remove the forking from Vildagliptin peak, a satisfactory separation of the three drugs Vildagliptin, Pioglitazone and Glimepiride was achieved using a mobile phase consisting of acetonitrile and $0.05 \mathrm{M}$ potassium dihydrogen phosphate buffer, $\mathrm{pH}=3.5$, in a final ratio of $(45: 55, \mathrm{v} / \mathrm{v})$.

\subsubsection{The effect of flow rate and wavelength - detection}

In regard to the flow rate optimization; it was initially set at $1 \mathrm{ml} / \mathrm{min}$, causing Glimepiride to be eluted too late at $>18 \mathrm{~min}$. Therefore, the flow rate was gradually increased until it was finally adjusted at $1.5 \mathrm{ml} / \mathrm{min}$ to separate Glimepiride at a reasonable time of $8.8 \mathrm{~min}$. This modification allows completing the process of separation of Vildagliptin, Pioglitazone and Glimepiride within ten minutes with better resolution.

Lastly, the wavelength of detection was set regarding the drugs UV absorption spectra and their relative concentrations within the pharmaceutical formulations. Where, 50:30:4 the ratio of Vildagliptin, Pioglitazone and Glimepiride respectively in the dosage form. This is why; an optimum detection wavelength was set at $200 \mathrm{~nm}$ during the chromatographic separation, favoring the separation and quantification of Vildagliptin and the quantification of Glimepiride, which represent the less concentrated component of this ternary mixture, achieving adequate signal strengths for the three analytes in respect to each other. In addition, such chosen detection wavelength greatly improves the sensitivity of the proposed method towards the Vildagliptin, since the later possess a high molar absorptive coefficient at $200 \mathrm{~nm}$.

The specificity of this HPLC method is illustrated at the typical chromatograms (Fig.5), where complete separation of the drugs was noticed. The average retention time \pm R.S.D. (\%) of Vildagliptin, Pioglitazone and Glimepiride were found to be; $1.268 \pm 0.159,2.71 \pm 0.322$ and $8.87 \pm 0.211$ min, respectively, for five replicates. The obtained peaks were sharp and had clear baseline separation. 


\section{Method Validation}

4.1 Linearity and range (calibration curve)

The linearity of an analytical procedure is its ability (within a given range) to obtain test results which are either, directly or through mathematical transformation proportional to the concentration of the analyte. This proposed HPLC method was assessed by least-squares linear regression analysis of the calibration curve [40]. According to the ICH guidelines [41], at least five concentrations must be used. In this presented study, five different concentrations, of each studied drug were chosen and prepared as previously discussed. Each concentration was injected in triplicate and the mean value of the peak areas was imputed into a Microsoft Excel $^{\circledR}$ spreadsheet program for the calibration curve plotting. The repeated runs were genuine repeats and not just repetitions at the same reading in which three replicate samples of each concentration level were prepared; this in order to provide information on the variation of the peak area between samples of the same concentration. The regression analyses revealed satisfactory correlations $(r=0.9996-0.9997)$, this, indicating a good linearity of the calibration graphs(Fig.5, 6\&7).Characteristic parameters for the regression equations of the HPLC method obtained by least-squares treatment of results were given in table (1).

\subsection{Precision}

The precision of the proposed HPLC analysis was evaluated as repeatability and reproducibility levels; using three independent concentrations of each drug. The repeatability (intra-day precision) studies were performed on the same day, whereas, that of the intermediate precision (inter-day precision) were checked by repeating these studies on three consecutive days. Every sample was injected in triplicates and both the retention times $\left(t_{\mathrm{R}}\right)$ and peak areas were determined. Within the examined time range, the peak area results presented in table (2) and show excellent precision for the method both during one analytical run and between different runs, with an intra-day and inter-day R.S.D. (\%), the range was $0.202-1.305$ and $0.262-1.327$, respectively.

\subsection{Detection and quantitation limits}

The limit of detection (LOD) for an HPLC method is the lowest drug concentration that produces a response detectable above the noise level of the system, typically taken as three times. The limit of quantification (LOQ) is the lowest level of the drug that can be accurately measured, and it is often evaluated as ten times the noise level. Both quantities were evaluated regarding the International Conference on Harmonization (ICH) guidelines [41]. Both the values of LOD and LOQ were assessed practically and given in table (1).

\subsection{Accuracy}

The accuracy of the proposed method, which is defined as the closeness or the nearness of the true and found values, was evaluated by measuring the drug recoveries by using the standard addition technique. The standard addition analysis involves the addition of three concentration levels of each drug standard solution (covering the linearity range and higher than LOQ) to pre-analyzed pharmaceutical samples containing; 25,15 and $2 \mu \mathrm{g} \mathrm{mL}^{-1}$ of Vildagliptin, Pioglitazone and Glimepiride respectively. Each set of addition was repeated five times, and the results obtained were compared with those expected from the calibration curve, table (3).

\subsection{Selectivity}

The selectivity of the proposed method was checked by preparing five laboratory-prepared mixtures of the studied drugs at various concentrations within their linearity range. The laboratory-prepared mixtures were analyzed according to the previous procedure described under the proposed method. Satisfactory results were obtained as listed in table (4) indicating the high selectivity of the proposed method for simultaneous determination of the studied drugs.

\subsection{Robustness}

Robustness relates to the capacity of the method to remain unaffected by small but deliberate variations introduced into the method critical parameters. For this, four chromatographic parameters such as; buffer $\mathrm{pH}$, organic composition of the mobile phase, elution flow rate and the detection wavelength were varied around the value set in the proposed method in order to reflect changes likely to arise in different testing environments. The $\mathrm{pH}$ was varied in the range 3.4-3.6 ( \pm 0.1 units), while as the mobile phase organic strength was varied through $\pm 1 \%(\mathrm{v} / \mathrm{v})$ alteration of the acetonitrile compositing proportions along the chromatographic separation. On the other hand, the influence of the flow rate was evaluated between $1.45-1.55 \mathrm{ml} / \mathrm{min}$, while as the detection wavelength was evaluated over $\pm 2 \mathrm{~nm}$ alterations. During the robustness study, only one factor was changed at a time and the analyses were performed in replicate injections $(n=3)$. The results, presented in table (5), confirm the method robustness since the observed variations were less than $1.401 \%$.

\subsection{System suitability test}

System suitability tests (SST) are based on the concept that the equipment, electronics, analytical operations and samples to be analyzed constitute an integral system that can be evaluated as such. These tests were performed in accordance with the BP guidelines to ensure adequate performance of both the chromatographic system and the equipment, for the analysis to be performed. The repeatability test was carried out by injecting six separated injections at concentrations 50,30, and $4 \mu \mathrm{g} / \mathrm{ml}$ regarding VILD, Pioglitazone, 
and Glimepiride. The observed R.S.D. (\%), of the retention times regarding these repetitive injections, was considered satisfactory, meeting the BP recommendation (R.S.D. $(\%)<1.0)$. Other chromatographic parameters were calculated from experimental data, such as; capacity factor $\left(k^{\prime}\right)$ also known as mass distribution ratio $\left(D_{\mathrm{m}}\right)$, tailing factor $\left(T_{\mathrm{f}}\right)$ also known as peak asymmetry factor $\left(A_{\mathrm{s}}\right)$ and the apparent number of theoretical plates $(N)$. All of these parameters are usually employed in assessing the performance of the column. Results obtained from system suitability tests are presented in table (6). Good agreement was found when results were compared with recommended values.

\subsection{Analytical solutions stability}

The solutions were stored in tightly capped volumetric flasks and wrapped with aluminum foil under reduced light conditions. It was found that Vildagliptin and Pioglitazone analytical solutions exhibited no changes for at least 10 days when stored refrigerated at $4^{\circ} \mathrm{C}$ and for 24 hours when kept at room temperature. Glimepiride analytical solution in methanol exhibited no changes for 7 days when stored refrigerated at $4^{\circ} \mathrm{C}$ and for 18 hours when kept at room temperature. Solutions of the studied compounds in the mobile phase exhibited no changes for 8 hours when kept at room temperature.

\subsection{Analysis of pharmaceutical products}

The validated HPLC method was applied for the determination of Vildagliptin, Pioglitazone and Glimepiride in pharmaceutical preparation using Gliptus ${ }^{\circledR}$ and Amaglust ${ }^{\circledR}$ tablets (Fig. 9). Three replicate determinations were performed at each concentration level. Satisfactory results were obtained for each compound in good agreement with label claims table (7). The obtained results were compared statistically by Student's $t$-test (for accuracy) and variance ratio F-test (for repeatability) with the reported method [7] for Vildagliptin \& [42] for Pioglitazone and Glimepiride. The results showed that the calculated $t$ and $F$ values were smaller than the critical values at $95 \%$ confidence limit indicating that there is no significant difference between the proposed and reported methods, table (7).

\section{Conclusion}

The proposed HPLC method provides simple, accurate and reproducible quantitative analysis for the simultaneous determination of pharmaceutical products containing Vildagliptin, Pioglitazone, and Glimepiride without any interference from excipients. The study showed that this chromatographic method is suitable for routine analysis of the studied compounds in their pharmaceutical preparations; the proposed RP-HPLC method is the first study for the simultaneous determination of Vildagliptin, Pioglitazone and Glimepiride as multi-drug pharmaceutical formulations providing a collective chromatographic profile regarding these three drugs. This, in turn, will be suitable as a guideline for the routine and QC analyses.

\section{Acknowledgement}

The authors sincerely thank to Dr. Eslam Hamed (central lab., Faculty of veterinary medicine/ Zagazige university) for his contributions.

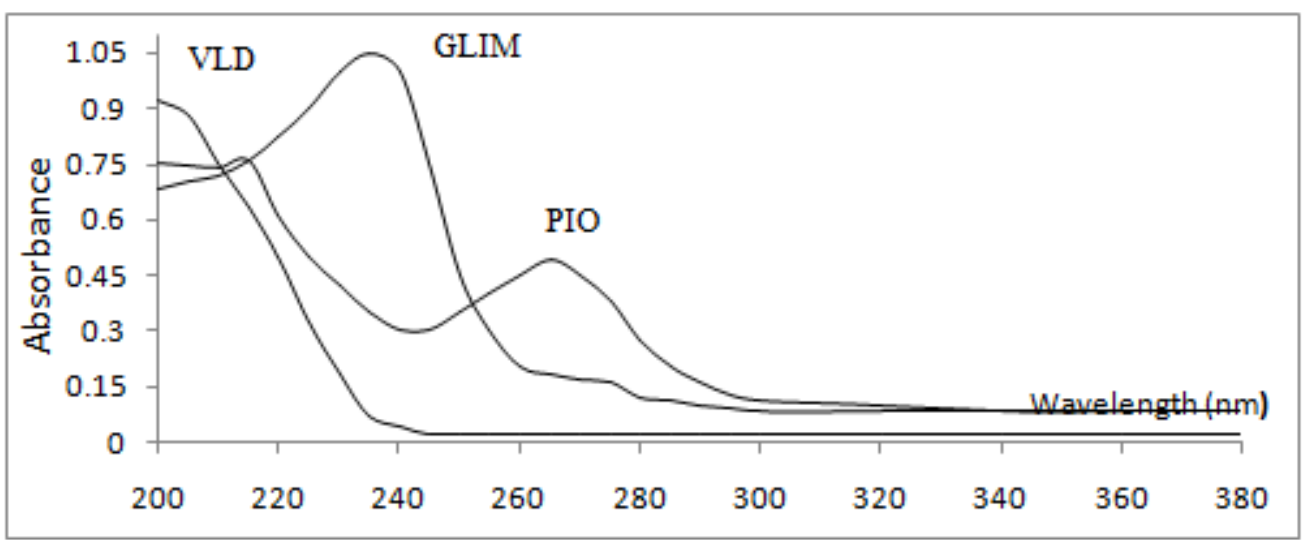

Fig.4: UV absorption spectra of $50 \mu \mathrm{g} / \mathrm{ml}$ Vildagliptin, Pioglitazone and Glimepiride in the mobile phase 


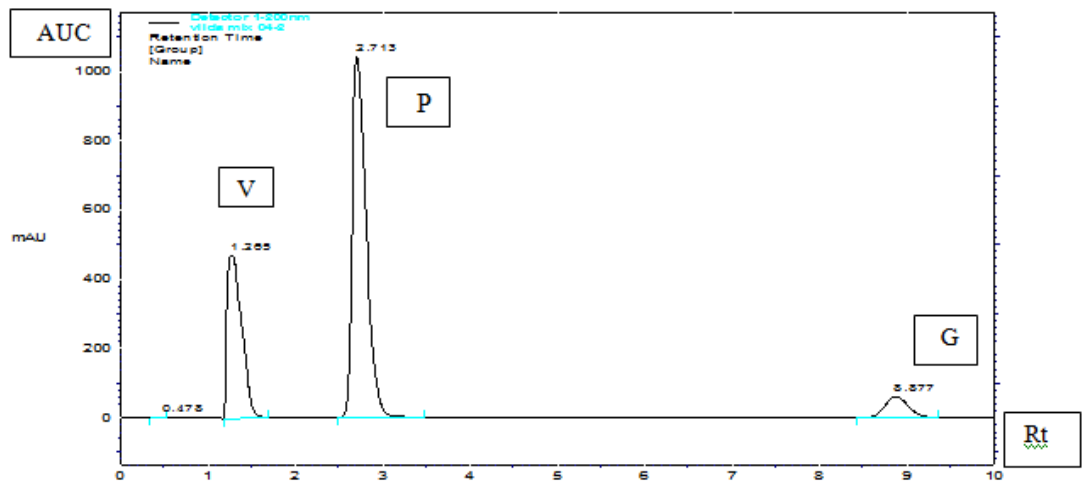

Fig. 5: HPLC Chromatogram of authentic mixture of Vildagliptin (V) $(50 \mu \mathrm{g} / \mathrm{ml})$, Pioglitazone $\mathrm{HCl}(\mathrm{P})(30$ $\mu \mathrm{g} / \mathrm{ml})$ and Glimepiride $(\mathrm{G})(4 \mu \mathrm{g} / \mathrm{ml})$ using the optimal conditions.

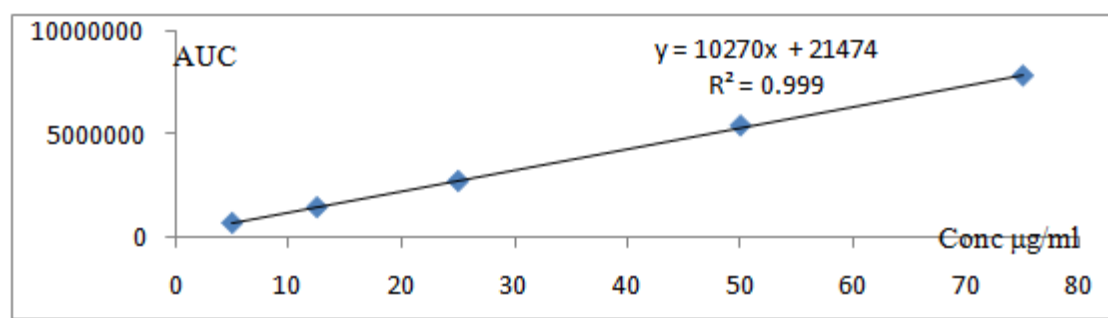

Fig.6: Calibration curve of Vildagliptin using the proposed HPLC method

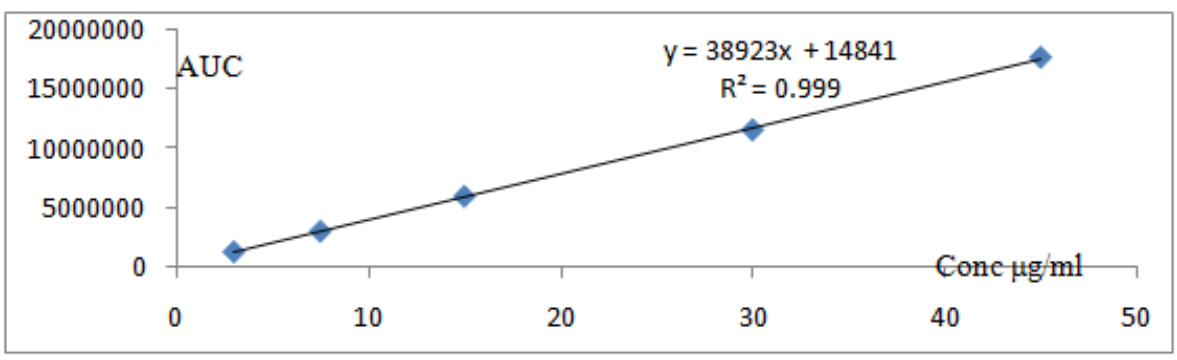

Fig.7: Calibration curve of Pioglitazone hydrochloride using the proposed HPLC method

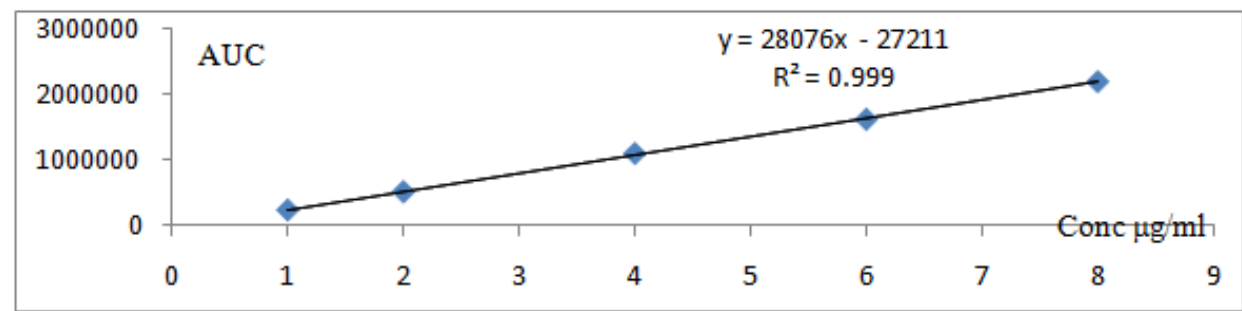

Fig.8: Calibration curve of Glimepiride using the proposed HPLC method

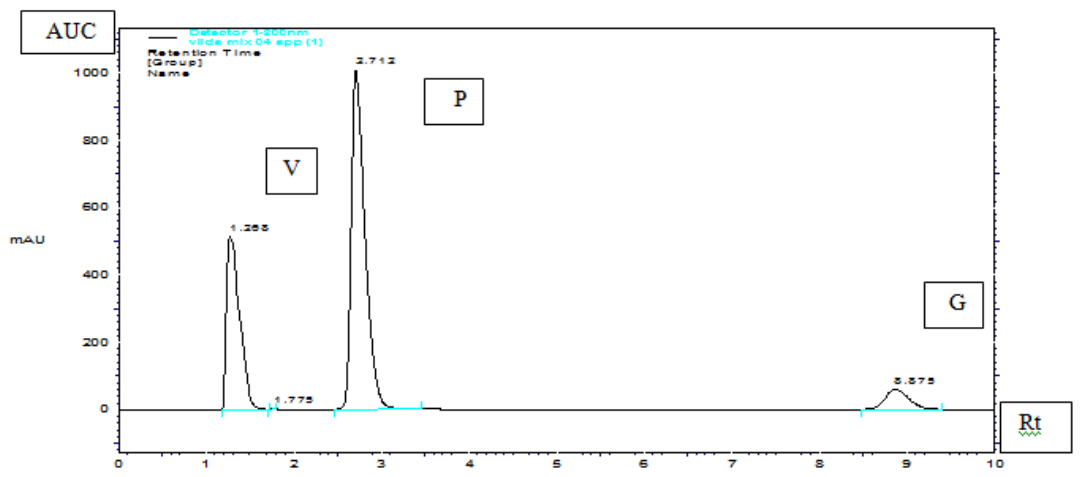

Fig.9: HPLC Chromatogram of the analysis of Gliptus ${ }^{\circledR}$ and Amaglust ${ }^{\circledR}$ tablets. 
Optimization and Validation of HPLC Method for Simultaneous Determination of Vildagliptin,

Table 1: Characteristic parameters for the calibration equations of the proposed HPLC method for the simultaneous determination of Vildagliptin, Pioglitazone and Glimepiride

\begin{tabular}{|l|l|l|l|}
\hline Parameters & Vildagliptin & Pioglitazone HCl & Glimepiride \\
\hline Linearity range $(\boldsymbol{\mu g} / \mathbf{m l})$ & $5-75$ & $3-45$ & $1-8$ \\
\hline Detection limit $(\boldsymbol{\mu g} / \mathbf{m l})$ & $9.27 \times 10^{-2}$ & $2.44 \times 10^{-2}$ & $3.39 \times 10^{-2}$ \\
\hline Quantitation limit $(\boldsymbol{\mu g} / \mathbf{m l})$ & $30.9 \times 10^{-2}$ & $8.15 \times 10^{-2}$ & $11.30 \times 10^{-2}$ \\
\hline Regression equation ${ }^{\text {a }}$ & \multicolumn{3}{|l|}{} \\
\hline Slope $(b)$ & $1.02702 \times 10^{5}$ & $3.89232 \times 10^{5}$ & $2.80762 \times 10^{5}$ \\
\hline Intercept $(\boldsymbol{a})$ & $2.14744 \times 10^{5}$ & $1.48417 \times 10^{5}$ & $2.7211 \times 10^{4}$ \\
\hline Correlation coefficient $(\mathbf{r})$ & 0.9996 & 0.9997 & 0.9997 \\
\hline
\end{tabular}

${ }^{a} \mathrm{Y}=a+b \mathrm{C}$, where $\mathrm{C}$ is the concentration of the reference standard substance $(\mu \mathrm{g} / \mathrm{ml})$ and $\mathrm{Y}$ is the peak area.

Table 2: Results of the intra-day and inter-day precision in the assay of Vildagliptin, Pioglitazone and Glimepiride using the proposed HPLC method

\begin{tabular}{|c|c|c|c|c|c|}
\hline \multirow[t]{2}{*}{ Drug } & \multirow{2}{*}{$\begin{array}{l}\text { Concentration } \\
\text { taken } \\
\mu \mathrm{g} / \mathrm{ml}\end{array}$} & \multicolumn{2}{|c|}{ Intra-day precision } & \multicolumn{2}{|c|}{ Inter-day precision } \\
\hline & & $\begin{array}{l}\text { Found } \\
\mu \mathrm{g} / \mathrm{ml}\end{array}$ & $\begin{array}{l}\text { Recovery (\%) } \quad \pm \text { S.D.; } \\
\text { R.S.D. }{ }^{a}(\%)\end{array}$ & $\begin{array}{l}\text { Found } \\
\mu \mathrm{g} / \mathrm{ml}\end{array}$ & $\begin{array}{l}\text { Recovery (\%) } \pm \text { S.D.; R.S.D. } \\
(\%)\end{array}$ \\
\hline \multirow{3}{*}{ VLD } & 12.5 & 12.59 & $100.76 \pm 1.315 ; 1.305$ & 12.51 & $100.07 \pm 0.579 ; 0.578$ \\
\hline & 50 & 49.69 & $99.39 \pm 0.833 ; 0.838$ & 49.68 & $99.36 \pm 0.861 ; 0.866$ \\
\hline & 75 & 75.38 & $100.50 \pm 0.649 ; 0.645$ & 75.45 & $100.60 \pm 0.743 ; 0.739$ \\
\hline \multirow{3}{*}{ PIO } & 7.5 & 7.51 & $100.19 \pm 0.565 ; 0.564$ & 7.56 & $100.88 \pm 0.264 ; 0.262$ \\
\hline & 30 & 30.12 & $100.42 \pm 1.03 ; 1.02$ & 30.39 & $101.31 \pm 0.524 ; 0.518$ \\
\hline & 45 & 45.47 & $101.04 \pm 0.204 ; 0.202$ & 45.23 & $100.53 \pm 0.511 ; 0.509$ \\
\hline \multirow[t]{3}{*}{ GLIM } & 1 & 0.997 & $99.77 \pm 0.656 ; 0.657$ & 0.992 & $99.26 \pm 0.550 ; 0.554$ \\
\hline & 4 & 4.01 & $100.29 \pm 0.561 ; 0.559$ & 4.03 & $100.69 \pm 0.856 ; 0.851$ \\
\hline & 6 & 6.01 & $100.17 \pm 0.807 ; 0.806$ & 6.00 & $100.02 \pm 1.328 ; 1.327$ \\
\hline
\end{tabular}

${ }^{a}$ Means, S.D. and R.S.D. (\%), of three replicates on same day. ${ }^{b}$ Means, S.D. and R.S.D. (\%), of three replicates on three consecutive days.

Table 3: Results of the accuracy studies by standard addition technique in the assay of Vildagliptin, Pioglitazone and Glimepiride using the proposed HPLC method $(\mathrm{n}=5)$

\begin{tabular}{|c|c|c|c|c|c|c|c|}
\hline \multirow[t]{2}{*}{ Drug } & \multicolumn{4}{|c|}{ Concentration $(\mu \mathrm{g} / \mathrm{ml})$} & \multirow{2}{*}{$\begin{array}{l}\text { Recovery } \\
(\%)\end{array}$} & \multirow{2}{*}{$\begin{array}{l}\text { R.S.D. } \\
(\%)\end{array}$} & \multirow{2}{*}{$\begin{array}{l}\text { Relative } \\
\text { error } \\
E_{\mathrm{r}}(\%)\end{array}$} \\
\hline & $\begin{array}{l}\text { Initial } \\
\text { tablet } \\
\text { sample }\end{array}$ & $\begin{array}{l}\text { Authentic } \\
\text { amount added }\end{array}$ & $\begin{array}{l}\text { Claimed total } \\
\text { amount }\end{array}$ & $\begin{array}{l}\text { Total amount } \\
\text { found } \\
\pm \text { S.D. }{ }^{\text {a }}\end{array}$ & & & \\
\hline \multirow[t]{3}{*}{ VLD } & 25 & 15 & 40 & $40.08 \pm 0.906$ & 100.52 & 0.901 & 0.08 \\
\hline & 25 & 30 & 55 & $54.85 \pm 0.278$ & 99.42 & 0.280 & -0.0027 \\
\hline & 25 & 50 & 75 & $74.82 \pm 1.196$ & 99.76 & 1.199 & -0.0024 \\
\hline \multirow[t]{3}{*}{ PIO } & 15 & 10 & 25 & $25.07 \pm 0.157$ & 100.27 & 0.156 & 0.0028 \\
\hline & 15 & 20 & 35 & $35.17 \pm 0.970$ & 100.48 & 0.965 & 0.0048 \\
\hline & 15 & 30 & 45 & $44.76 \pm 1.476$ & 99.46 & 1.484 & -0.0053 \\
\hline \multirow[t]{3}{*}{ GLIM } & 2 & 2 & 4 & $4.01 \pm 1.064$ & 100.34 & 1.061 & 0.0025 \\
\hline & 2 & 4 & 6 & $6.04 \pm 1.180$ & 100.76 & 1.172 & 0.0066 \\
\hline & 2 & 6 & 8 & $8.02 \pm 1.696$ & 100.30 & 1.691 & 0.0025 \\
\hline
\end{tabular}


Optimization and Validation of HPLC Method for Simultaneous Determination of Vildagliptin,

Table 4: Determination of Vildagliptin, Pioglitazone and Glimepiride in laboratory prepared mixtures using the proposed HPLC method

\begin{tabular}{|c|c|c|c|c|c|c|c|c|}
\hline \multicolumn{3}{|l|}{ VLD* } & \multicolumn{3}{|l|}{ PIO* } & \multicolumn{3}{|c|}{ GLIM* } \\
\hline Taken $\mu \mathrm{g} / \mathrm{ml}$ & $\begin{array}{l}\text { Area } \\
\text { under } \\
\text { peak }\end{array}$ & Recovery \% & $\begin{array}{l}\text { Taken } \\
\mu \mathrm{g} / \mathrm{ml}\end{array}$ & $\begin{array}{l}\text { Area under } \\
\text { peak }\end{array}$ & Recovery \% & $\begin{array}{l}\text { Taken } \\
\mu \mathrm{g} / \mathrm{ml}\end{array}$ & $\begin{array}{l}\text { Area } \\
\text { under } \\
\text { Peak }\end{array}$ & Recovery \% \\
\hline 5 & 721973 & 98.77 & 3 & 1341968 & 102.21 & 1 & 249238 & 98.46 \\
\hline 12.5 & 1486838 & 99.09 & 7.5 & 3077022 & 100.32 & 2 & 529647 & 99.17 \\
\hline 25 & 2757208 & 99.02 & 15 & 6030616 & 100.74 & 4 & 1117143 & 101.89 \\
\hline 50 & 5446751 & 101.88 & 30 & 11642159 & 98.43 & 6 & 1643848 & 99.19 \\
\hline 75 & 7863473 & 99.29 & 45 & 17768165 & 100.59 & 8 & 2220075 & 100.05 \\
\hline Mean & & 99.615 & & & 100.46 & & & 99.75 \\
\hline \pm SD & & 1.283 & & & 1.352 & & & 1.322 \\
\hline \pm RSD & & 1.288 & & & 1.346 & & & 1.325 \\
\hline \pm SE & & 0.485 & & & 0.511 & & & 0.50009 \\
\hline Variance & & 1.647 & & & 1.828 & & & 1.749 \\
\hline
\end{tabular}

* Average of five independent procedures.

Table 5: Results of the robustness evaluation in the assay of Vildagliptin, Pioglitazone and Glimepiride using the proposed HPLC method $(n=3)$

\begin{tabular}{|c|c|c|c|c|}
\hline Parameters & & VLD $(50 \mu \mathrm{g} / \mathrm{ml})$ & PIO $(30 \mu \mathrm{g} / \mathrm{ml})$ & GLIM(4 $\mu \mathrm{g} / \mathrm{ml})$ \\
\hline & Value & $\begin{array}{l}\text { Mean recovery }{ }^{\mathrm{a}}(\%) \pm \\
\text { R.S.D. }(\%)\end{array}$ & $\begin{array}{l}\text { Mean recovery }{ }^{\mathrm{a}}(\%) \pm \\
\text { R.S.D. }(\%)\end{array}$ & $\begin{array}{l}\text { Mean recovery }{ }^{\mathrm{a}}(\%) \pm \\
\text { R.S.D. }(\%)\end{array}$ \\
\hline \multirow[t]{2}{*}{ Flow rate } & 1.45 & $99.33 \pm 0.291$ & $100.73 \pm 0.800$ & $99.80 \pm 0.787$ \\
\hline & 1.55 & $100.59 \pm 0.130$ & $101.34 \pm 0.455$ & $100.75 \pm 0.483$ \\
\hline \multirow[t]{2}{*}{ ACN: Buffer } & $44: 56$ & $99.78 \pm 0.196$ & $100.47 \pm 0.152$ & $99.51 \pm 0.109$ \\
\hline & $46: 54$ & $100.35 \pm 1.179$ & $99.71 \pm 0.873$ & $100.07 \pm 0.510$ \\
\hline \multirow[t]{2}{*}{ pH } & 3.4 & $99.58 \pm 1.191$ & $100.66 \pm 0.857$ & $100.22 \pm 0.934$ \\
\hline & 3.6 & $99.45 \pm 0.772$ & $99.89 \pm 0.413$ & $100.40 \pm 1.07$ \\
\hline Wavelength(nm) & 202 & $99.14 \pm 0.679$ & $99.98 \pm 1.401$ & $100.31 \pm 0.944$ \\
\hline
\end{tabular}

${ }^{a}$ Each mean value was compared with the mean value obtained under optimum conditions

Table 6: Results of the statistical analysis parameters required for system suitability testing using the proposed

\begin{tabular}{|l|l|l|l|l|}
\hline Parameter & VILD & PIO & GLIM & Recommended values \\
\hline Retention time $\left(t_{\mathrm{R}}\right)(\mathrm{min})$ & 1.27 & 2.71 & 8.87 & - \\
\hline Tailing factor $\left(T_{\mathrm{f}}\right)$ & 1.33 & 0.92 & 1.16 & $0.8<T_{f} \leq 1.5$ \\
\hline Capacity factor $\left(k^{\prime}\right)$ & 0.66 & 1.51 & 2.95 & $0.5<k^{\prime}<10$ \\
\hline Theoretical plates No. $(N)$ & 257 & 1331 & 5095 & $\begin{array}{l}\text { The more plates, the better separation } \\
\text { efficiency }\end{array}$ \\
\hline R.S.D. $(\%)$ for six separate injections & 0.773 & 0.454 & 0.283 & $\leq 1$ \\
\hline
\end{tabular}


Table 7: Statistical comparison between the proposed HPLC method and reported methods for the determination of Vildagliptin, Pioglitazone and Glimepiride in Gliptus ${ }^{\circledR}$ and Amaglust ${ }^{\circledR}$ tablets

\begin{tabular}{|c|c|c|c|c|c|c|c|}
\hline \multirow[t]{2}{*}{ Analyte } & \multirow{2}{*}{$\begin{array}{l}\text { Amount taken } \\
\mu \mathrm{g} / \mathrm{ml}\end{array}$} & \multicolumn{2}{|c|}{ Proposed method } & \multicolumn{2}{|c|}{ Reportedmethods $^{\text {b }}$} & \multirow{2}{*}{$\begin{array}{l}t \text {-test } \\
(2.31)^{*}\end{array}$} & \multirow{2}{*}{$\begin{array}{l}F \text {-test } \\
(6.39)^{*}\end{array}$} \\
\hline & & $\begin{array}{l}\text { Recovery (\%) } \\
\pm \text { S.D. }{ }^{a}\end{array}$ & $\begin{array}{l}\text { R.S.D. }{ }^{a} \\
(\%)\end{array}$ & $\begin{array}{l}\text { Recovery (\%) } \\
\pm \text { S.D. }^{a}\end{array}$ & R.S.D. ${ }^{a}(\%)$ & & \\
\hline \multirow[t]{3}{*}{ VLD } & 12.5 & $100.42 \pm 0.437$ & 0.435 & $99.56 \pm 1.303$ & 1.309 & 0.143 & 0.057 \\
\hline & 25 & $100.59 \pm 0.901$ & 0.896 & $100.00 \pm 1.078$ & 1.078 & 0.377 & 0.108 \\
\hline & 50 & $99.47 \pm 0.273$ & 0.275 & $99.96 \pm 1.275$ & 1.276 & 0.446 & 0.011 \\
\hline \multirow[t]{3}{*}{$\mathrm{PIO}$} & 7.5 & $99.34 \pm 0.831$ & 0.837 & $100.46 \pm 1.871$ & 1.865 & 0.290 & 0.127 \\
\hline & 15 & $99.96 \pm 0.387$ & 0.387 & $101.02 \pm 1.429$ & 1.415 & 0.179 & 0.032 \\
\hline & 30 & $98.22 \pm 0.195$ & 0.198 & $100.38 \pm 1.385$ & 1.379 & 0.0236 & 0.039 \\
\hline \multirow[t]{3}{*}{ GLIM } & 1 & $99.30 \pm 0.530$ & 0.534 & $100.13 \pm 1.387$ & 1.385 & 0.316 & 0.108 \\
\hline & 2 & $99.68 \pm 0.546$ & 0.548 & $99.79 \pm 1.49$ & 1.50 & 0.887 & 0.129 \\
\hline & 4 & $100.46 \pm 1.060$ & 1.055 & $101.11 \pm 1.465$ & 1.449 & 0.458 & 0.622 \\
\hline
\end{tabular}

a. Average of five determinations.

b. Reported method [7] for Vildagliptin and [42] for Pioglitazone and Glimepiride respectively.

* Tabulated $\mathrm{t}$ and $\mathrm{F}$ values at $95 \%$ confidence limit

\section{References}

[1]. E. Bosi, F. Dotta, Y. Jia, and M. Goodman, Vildagliptin plus metformin combination therapy provides superior glycaemic control to individual monotherapy in treatment of patients with type 2 diabetes mellitus. Diabetes, Obesity and Metabolism journal, 11(5), 2009, 506-515.

[2]. A. Schweizer, S. Dejager, and E. Bosi, Comparison of vildagliptin and metformin monotherapy in elderly patients with type 2 diabetes: a 24-week, double-blind randomized trial. Diabetes, Obesity and Metabolism journal, 11(8), $2009,804-812$.

[3]. A. Patwari, B. Suhagia, and R. Solanki, Extractive spectrophotometric method for determination of dipeptidyl peptidase-4 inhibitors in bulk and their pharmaceutical dosage forms. Indo American Journal of Pharmaceutical Research, 3(11), $2013,9059-9066$.

[4]. M.S. Moneeb, Spectrophotometric and spectrofluorimetric methods for the determination of saxagliptin and vildagliptin in bulk and pharmaceutical preparations. Bulletin of Faculty of Pharmacy, Cairo University, 51(2), 2013, 139-150.

[5]. B. Shrikrishna, S. Mulgund, and N. Ranpise, Simultaneous spectrophotometric estimation of Vildagliptin and Metformin in bulk and tablet dosage form. Der pharmachemica, 5(1), 2013, 24-27.

[6]. U. Gundala, C.S. Bhuvanagiri, and D. Nayakanti, Simultaneous estimation of Vildagliptin and Metformin in bulk and pharmaceutical formulations by UV spectrophotometry. American Journal of Pharm Tech Research, 3(1), 2013, 339-344.

[7]. P.R. Satpathy, V.M. Goud, B. Bhagya, JVC. Sharma, and N. Shyamala Development and validation of a RP-HPLC method for the assay of vildagliptin. World Journal of Pharmacy and Pharmaceutical Sciences, 3(2), 2013, 2303-2310.

[8]. A. Malakar, B. Bokshi, and D. Nasrin, Development and validation of RP-HPLC method for estimation of vildagliptin from tablet dosage form. International journal of pharmaceutical and life sciences, 1(1), 2012, 1-8.

[9]. R. Khatun and M. Mirazzunnabi, A validated reversed-phase HPLC method for the determination of vildagliptin from tablet dosage form. International Journal of Pharmaceutical and Life Sciences, 2(3), 2013, 90-98.

[10]. R.I. El-Bagary, E.F. Elkady, and B.M. Ayoub, Liquid chromatographic methods for the determination of vildagliptin in the presence of its synthetic intermediate and the simultaneous determination of pioglitazone hydrochloride and metformin hydrochloride. International journal of biomedical science, 7(3), 2011, 201-208.

[11]. P.G. Shelke, A.P. Dewani, R.L. Bakal, S.N. Vasu, A.S. Tripathi and A.V. Chandewar, A validated RP-HPLC method for simultaneous determination of metformin $\mathrm{HCl}$ and vildagliptin in pharmaceutical formulation. International Journal of Advances in Pharmaceutical Analysis, 3(2), 2013, 37-41.

[12]. G.M. Prathap, M. Muthukumaran, and B. Krishnamoorthy, Development and validation of simultaneously estimation of vildagliptin and metformin hydrochloride by RP-HPLC in bulk and oral dosage form. Int J Adv Pharm Gen Res, 2 (1), $2014,24-33$.

[13]. Ramzia I. El Bagary, Hassan M. E. Azzazy, Ehab F. ElKady and Faten Farouk, Simultaneous determination of metformin, vildagliptin, and 3-amino-1-adamantanol in human plasma: application to pharmacokinetic studies. Journal of Liquid Chromatography \& Related Technologies, 39(4), 2016, 195-202.

[14]. Eman I. El-Kimary, Dalia A. Hamdy, Sara S. Mourad and Magda A. Barary, HPTLC determination of three gliptins in binary mixtures with metformin, Journal of Chromatographic science, 54 (1), 2015: 2016, 79-87.

[15]. R.S. Satoskar, N. Rege, and S. Bhandarkar, Pharmacology and pharmacotherapeutics(Elsevier Health Sciences: 2015).

[16]. USP 36 NF31, U. S. Pharmacopoeia National Formulary 31-Official monographs /Pioglitazone and Glimepiride, 2013 pp.4807 and 3730

[17]. L. Goswami, S. Mukhopadhyay, and S. Durgapal, Simultaneous estimation of metformin and pioglitazone by ultraviolet spectrophotometry, Indian journal of pharmaceutical sciences, 72(4), 2010, 508-510.

[18]. K. Sujana, G. Swathi Rani, M. Bhanu Prasad, M. Saheethi Reddy and K. Sujana, Simultaneous estimation of pioglitazone hydrochloride and metformin hydrochloride using UV spectroscopic method. J Biomed Sci and Res, 2(2), 2010, 110-115.

[19]. O.S. Havele, and S.S. Havele, Simultaneous determination of atorvastatin calcium and pioglitazone hydrochloride in its multicomponent dosage forms by UV spectrophotometry. International Journal of Pharmacy and Pharmaceutical Science Research, 1(2), 2011, 75-79. 
[20]. P. Basniwal, P. Srivastava, and D. Jain, Spectrophotometric estimation of pioglitazone hydrochloride in tablet dosage form. Asian Journal of Pharmaceutics, 2(4), 2008, 225-227.

[21]. D. SonaliRathod, P.M. Patil, S. B. Jadhav and P.D. Chaudhari, UV spectrophotometric simultaneous determination of metformin hydrochloride and pioglitazone hydrochloride in combined dosage form. Asian Journal of Pharmaceutical Analysis, 2(1), 2012, 0509.

[22]. Deepti Jain, Surendra Jain, Deepak Jain, and Maulik Amin, Simultaneous estimation of metformin hydrochloride, pioglitazone hydrochloride, and glimepiride by RP-HPLC in tablet formulation. Journal of chromatographic science, 46(6), 2008, 501-504.

[23]. A.T.O. Mahatma, and M. Joshi, A validated RP-HPLC method for simultaneous determination of metformin $\mathrm{HCl}$, pioglitazone $\mathrm{HCl}$ and glimepiride in pharmaceutical formulation. Journal of Pharmaceutical Research \& Opinion, 3(11), 2014, 82-96.

[24]. P. Raja, J. C. Thejaswini, B. M. Gurupadayya and K. Sowjanya, Determination and validation of metformin, glimepiride, and pioglitazone using atorvastatin as an Internal standardin bulk drug and pharmaceutical dosage form. Journal of Applied Chemical Research, 18, 2011, 61-68.

[25]. J.R. Patel, B.N. Suhagia, and M.M. Patel, Simultaneous estimation of glimepiride and pioglitazone in bulk and in pharmaceutical formulation by HPTLC method. Asian Journal of Chemistry, 18(4), 2006, 2873-2878.

[26]. M.A. Jiladia, S. Pandya, and G. Viidyasagar, A simple and sensitive HPTLC method for estimation of pioglitazone In bulk and tablet dosage forms. Asian Journal of Research in Chemistry, 2(2), 2009, 207-209.

[27]. British Pharmacopeia, G., (PhEur monograph 2223), 2013.

[28]. SakalaBhargavi, GopisettySuryasagar, Dantu Krishna Sowmya, Kota Ashok and SreekanthNamal, UV spectrophotometric method for determination of glimepiride in pharmaceutical dosage forms. International Journal of Pharmaceutical Sciences Review and Research, 21(2), 2013, 131-133.

[29]. R. Bonfilio, M.B.d. Araújo, and H. Salgado, Development and validation of an UV-derivative spectrophotometric method for determination of glimepiride in tablets. Journal of the Brazilian Chemical Society, 22(2), 2011, 292-299.

[30]. S. Altinöz, and D. Tekeli, Analysis of glimepiride by using derivative UV spectrophotometric method. Journal of pharmaceutical and biomedical analysis, 24(3), 2001, 507-515.

[31]. A. Goyal, and I. Singhvi, Simultaneous spectrophotometric estimation of rosiglitazone maleate and glimepiride in tablet dosage forms. Indian Journal of Pharmaceutical Sciences, 69(6), 2007, 780-783.

[32]. P. Khedekar, S. Dhole, and K. Bhusari, Application of vierodt's and absorption correction spectrophotometric methods for estimation of rosiglitazone maleate and glimepiride in tablets. Digest Journal of Nanomaterial and Biostructures, 4(4), 2009, 739746.

[33]. AudumbarDigambar Mali, Seeta Mali, AshpakTamboli and Ritesh Bathe, Simultaneous UV spectrophotometric methods for estimation of metformin $\mathrm{HCl}$ and glimepiride in bulk and tablet dosage form. International Journal of Advances in Pharmaceutics, 4(6), 2015, 117-124.

[34]. Mamdouh R. Rezk, Safa'a M. Riad, Ghada Y. Mahmoud and Abdel-Aziz El Bayoumi Abdel Aleem, Simultaneous determination of pioglitazone and glimepiride in their pharmaceutical formulations. Journal of Applied Pharmaceutical Science, 2(5), $2012,177-184$.

[35]. M. PatilPallavi, R. Sonali, and C. Praveen, Development and validation of UV derivative spectrophotometric method for determination of glimepiride, metformin $\mathrm{Hcl}$, pioglitazone $\mathrm{HCl}$ In bulk and marketed formulation. Journal of Pharmaceutical \& Scientific Innovation, 1, 2012, 58-62.

[36]. Nahed M El-Enany, Amina A Abdelal, Fathalla F Belal,Yoshinori I Itoh and Mitsuhiro N Nakamura, Development and validation of a reversed phase-HPLC method for simultaneous determination of rosiglitazone and glimepiride in combined dosage forms and human plasma. Chemistry central journal, 6(1), 2012, 1-6.

[37]. V. Maslarska, Development, estimation and validation of glimepiride in pharmaceutical formulation by HPLC method. International Journal of Pharmaceutical Sciences and Research, 5(8), 2014, 3195-3198.

[38]. K.K. Patel, V.V. Karkhanis, and S.S. Gajjar, Development and validation of stability indicating HPTLC method for estimation of glimepiride and metformin hydrochloride. International Journal of Pharmaceutical Sciences and Research, 6(3), 2015, $1222-1229$.

[39]. K. Alagawadi, and A.M. Kumar, HPTLC method for the simultaneous estimation of atorvastatin, glimepiride and metformin in combined dosage form. Journal of Pharmaceutical and Biomedical Sciences, 7(07), 2010. 1-4.

[40]. J.N. Miller, Basic statistical methods for analytical chemistry. Part 2. Calibration and regression methods. A review. Analyst, 1991. 116(1): p. 3-14.

[41]. International Conference on Harmonization of Technical Requirements for Registration of Pharmaceuticals for Human Use, ICH Harmonized Tripartite Guideline-Validation of Analytical Procedures: Text and Methodology Q2(R1), Current Step 4 version, London, 2005.

[42]. M. S. V. Sakuntala, S. V. U. M. Prasad, S. Sri Devi, S. Kishore Yadav, K. Srinivas Reddy, A RP-HPLC method development and validation for the simultaneous estimation of glimepiride and pioglitazone $\mathrm{HCl}$ in tablet dosage forms. Journal of Chemical and Pharmaceutical Research, 4(1), 2012, 154-159 